\title{
The art of company financial modelling
}

\author{
Zoran Lukić ${ }^{1, \dagger}$ \\ ${ }^{1}$ Investment Banking, Zagrebačka banka, Savska 60, 10000 Zagreb, Croatia \\ E-mail: 〈Zoran.Lukic@unicreditgroup.zaba.hr〉
}

\begin{abstract}
In corporate finance, the term financial modelling denotes a widely used technique of comprehensive customised quantification of a company's entire operations. Even though not mathematically strict, such models exhibit descriptive, explanatory and predictive qualities. The paper elaborates on the main steps and principles for building financial models of companies. It also identifies required assumptions and certain statistical properties of well-constructed models. Furthermore, it describes the use of such models for decision support purposes, supplemented by an illustrative example. Finally, it discusses general characteristics and concerns associated with appropriate model construction and use.
\end{abstract}

Keywords: financial modelling, corporate finance, decision support, business plan, fundamental analysis

Received: September 30, 2016; accepted: July 18, 2017; available online: November 30, 2017

DOI: $10.17535 /$ crorr.2017.0026

\section{Introduction}

The title resembles a stereotyped expression describing financial modelling of a company as "more of an art than a science". This perceived duality is further supported by a review of the literature. On the one hand, a large number of practical tutorials are available, but limited to the constructional aspect of such modelling. On the other hand, extensive academic research is restricted to financial forecasts resulting from such models, and provided by publicly available equity analyst reports. An integrated approach, connecting both the modelling process and output analysis is the motivation behind this paper.

This paper presents a broad corporate use of company financial models, as evident from previous research, supported by a survey conducted among several large Croatian companies. It continues with a description of the constructional concept of a model, including model assumptions and inherent statistical properties of standard model structures. Furthermore, the purpose of establishing models and

\footnotetext{
$\dagger$ Corresponding author
} 
its applications are also presented using the example of a company modelled for valuation purposes. Finally, a discussion on characteristics supports the adequacy of such models for the purposes presented in this paper, subject to the reasonable and responsible approach of both authors and users of the models.

\section{Financial modelling in literature and practice}

In general, financial modelling involves replicating the characteristics, behaviour and financial implications of a single financial asset or portfolio of assets, ranging from loan and lease agreements to various securities and derivatives. The classical models, such as Markowitz portfolio selection and Black-Scholes option pricing, are part of standard academic syllabi (e.g. [2]). Given that "time and uncertainty are the central elements that influence financial behaviour" [32], a considerable amount of literature is devoted to the modelling of financial assets as time series, using stochastic mathematical apparatuses (e.g. [34], [52]), as well as neural network architectures (e.g. [54]).

As opposed to various other asset classes, equity securities by definition exclude pre-defined cash flows to holders, suitable for modelling. Instead, the aim of equity modelling is assessment of security value, using the two different main approaches: technical analysis, for listed securities, and fundamental analysis, applicable also to non-listed ownership stakes. Technical theory assumes that "market value is determined solely by the interaction of supply and demand" [28] and focuses, therefore, exclusively on market data time series (prices and volumes of traded securities). In contrast, fundamental theory "believes that each security has an intrinsic value which depends upon its earning potential" [28], and is primarily interested in the underlying company and economic factors that influence its financial results.

Conceptualised in the 1930s [49], the fundamental analysis was initially restricted to a company's past and present [23], but has subsequently been extended to projections of future business performance [51]. The principal tool and prerequisite for this type of analysis is decomposition of a business into factors, replication of its past and forecast of the future in the form of a quantified model. In addition to investment purposes, the same modelling principles are applied for internal corporate business planning, with particularly rapid development alongside computer technology in the 1970s and 1980s [46], [35]. Simultaneously, it attracted significant attention from operational researchers (e.g. [37], [46], [27], [38], [36] and [20]). Consequently, a practical technique emerged, specialised for designing and using company financial models, interchangeably also referred to as corporate planning models (business plans). To distinguish it from other types of financial models, the term Company Financial Model (CFM) is used further in the text. 
Literature on equity investment analyses differentiates between sell-side and buyside research (e.g. [15], [25] and [24]). The former is performed by investment banks and is generally available to the public, whereas the latter is private and confidential, produced by investors themselves, or their advisors. Numerous research papers on sell-side analysis have investigated its accuracy (e.g. [7], [22] and [5]) and impact on financial markets (e.g. [9], [29] and [30]). While explicitly or implicitly recognised that CFM's are the underlying tools for both kind of investment analyses, recent papers have primarily addressed the outputs of such models, i.e. published financial projections of companies. Except for a few cases (e.g. [53]), the interest of contemporary research in inherent design, properties and characteristics of CFM's has decreased.

Disproportionally to recent academic research, there is an abundance of practical tutorials and training material (e.g. [6], [45], [50], [4], [14] and [3]), providing detailed guides and descriptions of steps for constructing and using CFMs. Moreover, the international financial modelling competition ModelOff was initiated in 2012, with several thousand participants getting involved annually.

To support the clear importance and penetration of CFM in corporations, a survey was conducted in September 2016 among 5 large Croatian companies: Adris Grupa, Atlantic Grupa, Hrvatski Telekom, Podravka and Zagrebačka banka. The participants were asked (i) whether they use financial modelling (for analysis, planning, valuation, financial management or other decision support purposes), and (ii) if yes, where did the modellers learn the required skills. For the survey, financial modelling was described as "the quantification of business operations (using spreadsheet programme) and aimed to replicate historical results and project the future business of the observed company", which is the proposed working definition of CFM. As expected, all participating companies confirmed the use of CFM, as described above. The frequency of the indicated sources of skills is summarised in the following table:

\begin{tabular}{|l|c|}
\hline Source of skills & $\#$ \\
\hline At the current or previous employer (colleagues or internal training) & 5 \\
\hline External training, course or professional specialisation (e.g. CFA) & 3 \\
\hline Education at domestic universities & 2 \\
\hline Education at foreign universities & 1 \\
\hline
\end{tabular}

Table 1: Sources of skills required for financial modelling (multiple answers possible); a survey among 5 large Croatian companies, September 2016

The survey results are consistent with the observed and previous findings [37] regarding the general acceptance of CFMs among corporations. The sources are consistent with the noticed practical, rather academic inclination. 
As a final remark, the author of this paper has had the privilege during his advisory career to build a number of CFMs for international institutional clients, and use them for various analytical and decision supporting purposes.

\section{Construction of a model}

A CFM is comprehensive quantification (numerical representation) of a certain business activity. It is designed to specifically represent a specific business entity, not a generalisation or abstraction applicable for various entities. Its form is a table (matrix) with columns representing time periods (usually fiscal years), and the rows containing different line items. The historical part shows results of past business events (actuals), while the future part displays a possible numerical realisation of future business events (forecasts, projections).

According to [14], "financial modelling is the construction and use of a spreadsheet depiction of a company's or an individual's past, present, or future business operations". A spreadsheet programme is the primary tools for constructing a CFM. The appearance and development of spreadsheets has catalysed modern financial modelling [4], enabling sequences of computational links between cells, as well as transparently displaying numerical inputs and outputs in real time. All business activities are represented by financial statements (balance sheet, income statement and cash flow statement). Financial statements are, therefore, the first element of a CFM. Furthermore, financial statements are monetary records of underlying business operations, quantified by various operational variables and indicators. These operational items are the second element of a CFM. Each financial line item has its corresponding operational factors, just as each event in an entity's real business life has financial consequences. The natural goal is, therefore, to establish functional links between operational and financial elements, which is the key constructive superstructure of CFM that transcends from a mere list of data into an organised logical system.

The first type of functional link is at a purely financial level and follows accounting rules. The second type is factorisation of financial items into quantities and prices, and subsequently, establishment of relations using macroeconomic or market indicators. Factorisation is crucial for all significant financial items, while less important items can be approximated or aggregated. The amount and depth of knowledge about a company directly impacts a modeller's ability to identify the importance relevant items and construct appropriate relations. An absence of these links significantly deteriorates the quality of the model.

The third type of link aims to establish functional relations between various operational variables. These relations are complex, controversial and generally unknown. For example, it is unclear a priori as to how exactly an incremental unit of advertising space influences aggregate demand, market share, product pricing and, ultimately, sales revenues. Furthermore, these relations largely 
depend on the specific sector, market and individual company, making them difficult to determine or possibly generalise. To establish reasonable functional relations, modellers use market studies, statistical analyses, approximations and heuristics, or rely on sector expertise and knowledge of inherent business logic.

Construction of a CFM begins with input of historical financials, and ends with projections of future financial statements, as stated in [3]: "a fully integrated model derives and projects the three main financial statements of a business". In the historical part, financial inputs are combined with various observable operational indicators to extract and define a limited set of main model drivers. An ideal CFM has only two kinds of drivers: (i) macroeconomic and market indicators (exogenous); and (ii) operational variables subject to a sole strategic (business, managerial) choice of the company (endogenous) [53]. The number of main drivers is significantly reduced by establishing the above-mentioned third type of links. In the future part of a CFM, construction continues in the opposite direction: only inputted forecasts are the main drivers. Projections of all other operational variables, quantities and prices depend on the driver forecasts, while the projected financial statements are the consequence of the former. A typical CFM construction plan is summarised in the following table:

\begin{tabular}{|c|c|c|}
\hline Step & Contents & Information source \\
\hline 1 & Model dimensioning & \\
\hline 2 & Input of historical financials and type 1 links & Financial audit \\
\hline 3 & $\begin{array}{c}\text { Identification of operational factors and type } 2 \\
\text { links }\end{array}$ & Due diligence \\
\hline 4 & Identification of drivers and type 3 links & $\begin{array}{c}\text { Sector and market } \\
\text { expertise }\end{array}$ \\
\hline 5 & Construction of deterministic financial routines & Due diligence \\
\hline 6 & $\begin{array}{c}\text { Forecast of drivers } \\
\text { drivers }\end{array}$ & $\begin{array}{c}\text { Sector and market } \\
\text { expertise }\end{array}$ \\
\hline 7 & Derivation of operational projections from & Due diligence \\
\hline 8 & Derivation of financial projections from \\
operational & Financial audit \\
\hline 9 & Model audit & \\
\hline
\end{tabular}

Table 2: Plan for constructing a CFM

The plan starts with preparatory step 1 , and ends with controlling step 9. As described earlier, steps related to the past $(2,3,4)$ extract information for the historical part, while steps related to the future $(6,7,8)$ construct projections for the future part of a CPM. In between these steps, the aim of step 5 is to build various computational financial routines (e.g. interest income and expense, debt 
repayment, dividend policy, depreciation and amortisation, tax levy and loss carry forward, potential revolving debt drawdown, etc.) which are pre-defined contractually, by legal and regulatory framework, or accounting rules.

To accomplish each step, the table indicates the most common information source. Regarding the financial level (steps 2,8), in principle it is sufficient to analyse the standard financial audit report with its accompanying notes. Assessment of the operational level (steps 3,7) requires having access to confidential business information. This information is collected and verified through commercial, technical and legal due diligence of the company (some portion of operational information may be available in periodic management reports). Additionally, the information for step 5 is obtained through financial and tax due diligence.

Finally, the assumptions level (steps 4,6) requires sector and market expertise. This means a deep knowledge and understanding of technological processes and the business model used by the company for transforming available resources and market circumstances into cash flows. As mentioned earlier, the tasks implemented at this level (identification of drivers, forecasts of drivers and establishment of type 3 links) are controversial and subject to a critique due to the lack of sufficient scientific grounds. For this reason, a competent sector and market expert is crucial for the implementation, not for acting as an undisputable authority, but to make reasonable assumptions where scientific evidence is not available.

\subsection{Model assumptions}

CFM assumptions consist of two subgroups: forecasts of the driving variables; and the relationships ("type 3 links") among them. Both are non-exact, hence controversial elements. The output of sell-side equity analysts' models is being continuously researched as to the accuracy of earnings forecasts, including tests whether the forecasts support rational expectations, adaptive expectations or implicit expectations hypothesis (e.g. [40], [1]). Many of them have detected systematic forecasting errors, thus rejecting the rationality hypothesis (e.g. [41], [8]). Several different ways of forecasting are listed in [16]: informal, expert judgement, extrapolation, leading indicators, surveys, time series and econometric systems of equations. In practice, the prevailing forecasting method is best described as an extended expert judgment; an opportune use of all, depending on the circumstances. For example, if an expert judges that a strong historical trend of a certain driving variable has a prevailing impact on the future, then the ex post tests would most likely indicate supporting evidence for the adaptive expectations hypothesis. It is not that the modeller has ex ante selected extrapolation as the forecasting method. Restricting the universe of available options prior to examination of each concrete modelling case is disadvantageous. Similar to 
forecasts, the judgment approach is used in constructing links between drivers: the assumed relationships are generally heuristic, approximate and robust.

Despite these severe methodological inconsistencies, sell-side analysts have been repeatedly reported as being superior in forecasting, compared to other predefined, theoretically well-founded approaches, such as univariate time series models ([39], [11], [10] and [12]). The practice indicates that automated or algorithmic forecasting methods, in absence of conclusive expert judgment, often result in the predictive deficiency of a CFM. Similarly, the theoretically unknown relation that has been despite constructed heuristically and controlled by the expert, can improve the predictive properties of a CFM.

\subsection{Statistical properties of the model}

In addition to judgmental forecasts, the constructional mechanics of a CFM has a significant impact on the statistical properties of projections, and is an area requiring further research.

Modellers intuitively recognise the benefits of disaggregated financial forecasts: the possible overstatement of one component is offset by the possible understatement of the other; thus a forecast error is reduced. For example, rather than forecasting total revenues, the CFM standard is to decompose and perform modelling of different revenue streams separately. In case separate forecasts (or forecast errors) form a sequence of independent stochastic variables (generally not identically distributed), which are uniformly bounded, with the sum of variances approaching infinity, then the Lindeberg condition is automatically satisfied and the Lindeberg-Feller Central Limit Theorem ensures that the standardised sum of such variables converges in distribution to a standard normal stochastic variable [44].

However, the variables in CFM are typically not independent, but interconnected crosswise. Nevertheless, the error variance is still reduced by disaggregation, if the variables are bounded and if the corresponding standard deviations have certain properties as the uniform distribution. Formally:

Proposition: Let the following bounded stochastic variables (generally not independent and not identically distributed) have the following support intervals for respective probability density functions:

$$
X \ldots[a, b] ; \quad X_{i} \ldots\left[a_{i}, b_{i}\right], i=1, \ldots, n ; \quad a=\sum_{i=1}^{n} a_{i}, \quad b=\sum_{i=1}^{n} b_{i} .
$$

Let the corresponding standard deviations depend only on the length of the support intervals, in the following form:

$$
\sigma_{X}=f(c), c=b-a ; \quad \sigma_{X_{i}}=f\left(c_{i}\right), c_{i}=b_{i}-a_{i}, i=1, \ldots, n
$$


Assume that function $f$ is superadditive where required. Then,

$$
\operatorname{Var} \sum_{i=1}^{n} X_{i} \leq \operatorname{Var} X .
$$

Proof:

$$
\begin{aligned}
& \operatorname{Var} \sum_{i=1}^{n} X_{i}=\sum_{i=1}^{n} f\left(c_{i}\right)^{2}+2 \sum_{i<j} \operatorname{Cov}\left(X_{i}, X_{j}\right) \\
& \quad \leq \sum_{i=1}^{n} f\left(c_{i}\right)^{2}+2 \sum_{i<j} f\left(c_{i}\right) \cdot f\left(c_{j}\right) \\
& =\left(\sum_{i=1}^{n} f\left(c_{i}\right)\right)^{2} \leq\left(f\left(\sum_{i=1}^{n} c_{i}\right)\right)^{2}=\operatorname{Var} X . \quad \text { Q.E.D. }
\end{aligned}
$$

Uniformly distributed, as do many other commonly used variables, comply with the above requirements, which are not overly restrictive. For example, all convex functions, non-positive at zero, are superadditive on the non-negative domain. Another variance reduction constructional property of CFMs is due to relationships between the driving variables ("type 3 links"). The CFM standard is to link different revenue streams with corresponding costs, to move in the same direction, thus avoiding "the free lunch" misconception. On a profit level, revenues and costs are subtracted. If revenues and costs are stochastic and positively correlated, the profit variance is decreased due to an altered covariance sign. This property is similar to antithetic variates method for variance reduction, as described in literature on Monte Carlo simulations (e.g. [43]).

\section{Uses of the model}

The historical part of a CFM is used for analysing past business performance, by controlling departments in advanced corporate organisations as well as external analysts. The CFM's quantifying completeness and conjunction of financial and operational factors provide a powerful managerial analytical base. It helps to identify and explain various hidden phenomena that influenced past results, ranging from trivial (e.g. accounting inconsistencies) to strategically important (e.g. changes in underlying key business drivers). Such analysis is essential in identifying the starting point and critical areas when designing a company's strategy.

The prerequisite for use of the future part is to input initial forecasted values of drivers, consisting of an estimated future macro/market scenario and a defined company strategy in the context of macro/market assumptions. The model then outputs future operational and financial implications of the chosen strategy. In subsequent iterations, the macro/market scenario can be altered and the strategy adjusted accordingly to optimise business performance projections. This optimi- 
zation procedure provides valuable support in the decision-making process for defining mid- to long-term strategic goals, as well as feasible trajectories of all components in a consistent manner.

An important purpose of a CFM is, therefore, selection, optimisation and evaluation of company strategy. This kind of quantified strategy is, on the other hand, an input for the model used for various other decision-supporting exercises. For example, CFM output can be further used for the following purposes: budgeting, business planning, investment decisions, return analysis, valuation, credit analysis, identification of synergies, integration and re-organisation analyses, profitability management, capital structure adjustments, identification of financing requirements, risk management, stress testing, financial management including solvency and liquidity, improvement of business processes, etc.

The use of the model starts with a fixed set of assumptions representing the most probable future, the base case. To assess the uncertainty of projections, the modelling tutorials (e.g. [4], [14], [45] and [50]) suggest a variation of the assumed inputs and observation of changes in model outputs. These experiments are referred to as sensitivity analysis, scenario analysis and simulation modelling [17].

Sensitivity analysis monitors changes in a model output resulting from the variation of a single input variable (i.e. its time series), while retaining others as unchanged. Scenario analysis applies several pre-defined input scenarios, with different input values for all variables. In addition to the base (the most probable) case, scenario analysis is regularly used to determine two other possible, yet extreme, working cases - the worst (pessimistic, downside) and the best (optimistic, upside).

Thus far, the three examined cases (worst, base, best) provide a slightly clearer view of future uncertainty, by indicating the range of possible outcomes and the mode. However, other statistical properties of future projections remain unexplained. Simulation modelling is, therefore, a natural extension of the analysis, whereby each input is modelled as a stochastic variable, by using a spreadsheet pseudorandom number generator. This approach requires additional assumptions regarding probability distributions of inputs, and appropriate transformation of generated pseudorandom numbers. In practice, however, the simulation can be simplified by assuming uniform distributions for all inputs. (This practice has been discussed in the previous section.) For this purpose, each input requires only the estimation of a realistic and possible range of outcomes (as in scenario analysis), provided by experienced company management or an educated sector/market expert. After running the simulation, generated outputs are organised into empirical distributions, suitable for applying standard statistical tests of various hypotheses and drawing probabilistic conclusions about business projections.

Any conclusions arising from the aforementioned experiments refer to the constructed model, not a real-world company. On the other hand, experimenting 
with an actual business is impossible. Therefore, if the model realistically replicates a company, the described techniques provide consistent analytical tools, to be used with an awareness of all the embedded advantages and limitations.

\subsection{An illustrative example}

This example demonstrates the benefits of modelling for company valuation, in the specific case of Slovak Telekom, the national integrated telecommunications operator in Slovakia. In May 2015, Deutsche Telekom announced the acquisition of the remaining $49 \%$ stake in Slovak Telekom from the Government of Slovakia for EUR 900 million, thus becoming the sole shareholder. The target company has not been listed, implying the non-existence of a reference market price, as well as lack of research incorporating financial projections and valuation. While both transaction parties had access to inside information necessary for modelling and valuation, this example relies only on publicly available information (e.g. the company's annual reports).

The standard method for valuing a minority stake is relative valuation using market multiples of comparable companies. A natural peer group here consists of listed incumbent operators in new EU members in neighbouring CEE. For valuation purposes, the financial indicators of Slovak Telekom are multiplied by the appropriate median market multiples from the following table:

\begin{tabular}{|l|c|c|c|c|c|c|}
\hline As of 31.03.2015 & $2012 \mathrm{~A}$ & $2013 \mathrm{~A}$ & $2014 \mathrm{~A}$ & $2015 \mathrm{~F}$ & $2016 \mathrm{~F}$ & $2017 \mathrm{~F}$ \\
\hline EV/Sales & $1.3 \mathrm{x}$ & $1.4 \mathrm{x}$ & $1.5 \mathrm{x}$ & $1.5 \mathrm{x}$ & $1.5 \mathrm{x}$ & $1.5 \mathrm{x}$ \\
\hline EV/EBITDA & $3.5 \mathrm{x}$ & $4.1 \mathrm{x}$ & $4.3 \mathrm{x}$ & $4.5 \mathrm{x}$ & $4.6 \mathrm{x}$ & $4.6 \mathrm{x}$ \\
\hline $\mathrm{P} / \mathrm{E}$ & $9.6 \mathrm{x}$ & $18.3 \mathrm{x}$ & $15.0 \mathrm{x}$ & $17.0 \mathrm{x}$ & $14.2 \mathrm{x}$ & $13.1 \mathrm{x}$ \\
\hline
\end{tabular}

Table 3: Median market multiples. The peer group consists of Magyar Telekom, O2 CZ (former Český Telecom) and Orange Polska (former Telekomunikacja Polska). For each peer, the multiples are computed as of 31 March 2015 (historical multiples are based on actual financials, while the forward-looking multiples are based on Bloomberg consensus estimates). The table contains the median values of computed peer multiples.

Although close, the median valuation range based solely on historical financials does not encompass the transaction value of EUR 900 million:

\begin{tabular}{|l|c|c|c|}
\hline EUR mn & $2012 \mathrm{~A}$ & $2013 \mathrm{~A}$ & $2014 \mathrm{~A}$ \\
\hline Sales & 827 & 809 & 768 \\
\hline EBITDA & 347 & 306 & 264 \\
\hline Net income & 63 & 49 & 44 \\
\hline Net cash & & & 676 \\
\hline
\end{tabular}

Table 4: Slovak Telekom historical financial performance. 


\begin{tabular}{|l|c|c|c|}
\hline EUR mn & Min. & Med. & Max. \\
\hline EV/Sales & 862 & 879 & 887 \\
\hline EV/EBITDA & 888 & 919 & 947 \\
\hline P/E & 296 & 321 & 442 \\
\hline Median & 862 & 879 & 887 \\
\hline
\end{tabular}

Table 5: Slovak Telekom 49\% equity value, based on market multiples applied on historical financials.

For the application of forward-looking multiples, the key financials are projected using the constructed company model. Without insight into operational details, the model is relatively simplistic. Revenue items are factorised into subscribers (quantities) and average revenue per access (prices), with subscribers being further linked to sector and market indicators (market share, service penetration, population). Expenditure items are modelled by margins only, except for regulatory costs. The exogenous drivers are benchmarked versus the peer markets, while the endogenous are forecasted consistently with sector standards and the company's strategy, broadly indicated by the management in the annual reports. As the "forward-looking multiples are more accurate predictors of value than historical multiples" [31], the median valuation range based on financial projections (including the projected net cash at 1Q 2015) expectedly contains the actual transaction value:

\begin{tabular}{|l|c|c|c|}
\hline EUR mn & Min. & Med. & Max. \\
\hline EV/Sales & 895 & 905 & 906 \\
\hline EV/EBITDA & 963 & 977 & 978 \\
\hline P/E & 523 & 558 & 670 \\
\hline Median & 895 & 905 & 906 \\
\hline
\end{tabular}

Table 6: Slovak Telekom's 49\% equity value, based on forward market multiples applied on projected 2015 - 2017 financials and Net debt (cash) as of $1 Q 2015$.

Both median valuation ranges (using actuals and projections) are relatively narrow. They do not reflect the uncertainty of assumptions, but only the different growth/profitability characteristics of target, compared to peers. Had the growth (profitability) been equal, the valuations would have been constant across the years (multiples).

The previous forward-looking valuation is based on fixed assumed future values of model variables (hereafter the "base" case). To assess future uncertainty, the scenario analysis observes two additional scenarios, the "low" and the "high" case. For that purpose, a total of 12 model variables are used as input drivers, and assigned additionally assumed low and high future values respectively. 
For the simulation analysis, the above mentioned 12 input drivers are modelled as random variables, each uniformly distributed on the previously defined lowhigh respective intervals. The simulation is implemented in Microsoft Excel, using the built-in pseudorandom number generator, and generated 10,000 times.

In addition to median, the scenario and simulation analysis is performed also for the weighted average, both taken from $3 \times 3$ forward multiples valuation results. The marginal weights for future years $(2015$ - 2017) as well as used multiples (sales, EBITDA and earnings) are selected according to assumed relative importance: $(1 / 2,1 / 3,1 / 6)$ for years, and $(1 / 3,1 / 2,1 / 6)$ for multiples, respectively.

As expected, the simulated median valuation is less dispersed than the weighted average. Despite inputs being uniformly distributed over identical ranges as for scenarios, the simulated Bayesian central 95\% credible intervals (as defined in [26] and [21]) are only $\pm 4.0 \%$ and $\pm 7.9 \%$ wide. For comparison, the ranges between the low and high case scenarios (equal to distribution support) are respectively 3.2 and 2.1 times wider.

The output results of the scenario and simulation analysis are summarised below:

\begin{tabular}{|l|c|c|}
\hline Scenario analysis: & Median & Wgt. Avg. \\
\hline Low case & 800 & 752 \\
\hline Base case & 905 & 889 \\
\hline High case & 1,028 & 1,050 \\
\hline \multicolumn{3}{|l|}{} \\
\hline Simulation model: & Median & Wgt. Avg. \\
\hline Mean & 903 & 889 \\
\hline Coeff. of variation & $2.1 \%$ & $4.3 \%$ \\
\hline 95\% credible int.: & $\pm 4.0 \%$ & $\pm 7.9 \%$ \\
\hline Minimum & 867 & 818 \\
\hline Maximum & 939 & 959 \\
\hline
\end{tabular}

Table 7: Scenario analysis and simulation modelling output, for median and weighted average valuation based on forward market multiples. 


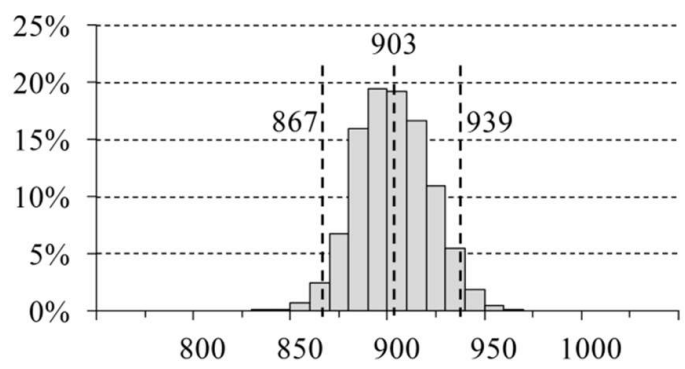

Figure 1: Median valuation: simulated output distribution histogram and central $95 \%$ credible interval.

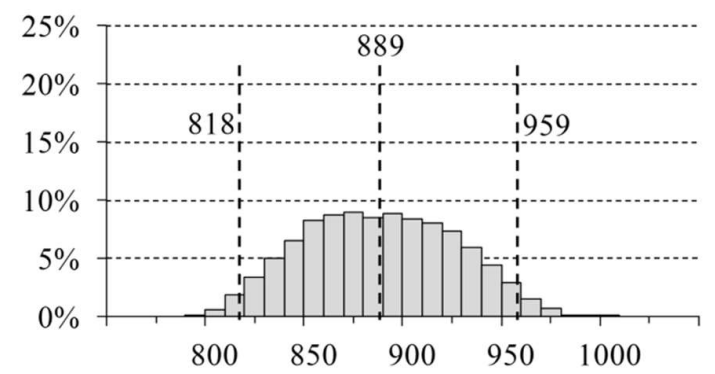

Figure 2: Weighted average valuation: simulated output distribution histogram and central 95\% credible interval.

The conclusion of the illustrative example is that, given the model and input distributions, the Slovak Telekom 49\% equity value on 31 March 2015 lies within EUR 867 - 939 million (median) or EUR 818 - 959 million (weighted average) with $95 \%$ probability.

\section{Discussion}

Are CFMs correctly called models? According to [19], models are miniature representations, imitations, descriptions that assist in visualisation. CFMs certainly are simplified replications of real businesses. Furthermore, the purpose of conceptual models is to describe, explain and predict reality [19]. Comprehensive quantification of a business obviously is a descriptive rationalisation that decreases the risk of inconsistency and incompleteness. Explanatory characteristics are achieved by decomposition of monetary aggregates first into quantities and prices, then into other underlying variables, with quantitative relationships among them. As emphasised in [27], "the equations comprising such models form a kind of knowledge base which can be used to generate explanations". Finally, CFMs (or, equivalently, corporate planning models) are by definition predictive models, with 
the objective to "provide (...) a forecast of what is likely to happen given the occurrence of certain events over which the managers have little or no control" [20]. Thus, the term model is justified.

Are CFMs mathematical models? Some authors are explicit that "a financial (planning) model is a mathematical model describing the interrelationships among financial variables of the firm" [48]. Moreover, "financial model is a system of mathematical equations, logic and data that describes the relationships among financial and operating variables", that falls "into two types: simulation, better known as 'what if' models, and optimization models" [47]. But, aren't mathematical models substantially more general and abstract constructs than CFMs? For example, the mathematical model for coin toss is a binary uniform random variable, while the mathematical model for vibration of an elastic rod is a partial differential equation with boundary-initial conditions. Both are appli-cable to any particular object, anytime. In contrast, each CFM is constructed for a specific company, for a particular point in time. It does not exist separately from the concrete object of application, and is not applicable to other objects. Naturally, a CFM itself is a system of equations, and it uses mathematical models as sub-tools, such as regression or time series analysis. Yet the primary purpose of CFMs is numerical representation of a single object, not a functional representation of the whole class. The reasons above indicate that CFMs do not qualify as mathematical models.

Attempts to increase generality or applicability of CFM typically result in a decrease of its explanatory and predictive qualities. It is the prevailing practice, therefore, to construct customised CFMs that are specific to one company only.

\subsection{Responsibility of modellers}

As CFMs are not well defined, but company-specific and subject to judgmental assumptions, the model structure and ultimately the output is at the discretion of modellers. But, isn't that unacceptably subjective and susceptible to manipulation? Research has detected examples of sell-side analyst bias, both behavioural and attributable to the conflicted interest (e.g. [42], [55] and [33]). However, in the European Union and other advanced jurisdictions, the release of sell-side equity research is an intensely regulated investment activity, subject to regulation by financial services authorities. Moreover, each research report is undersigned by its author, providing the name and contacts for possible inquiries. In addition to legal requirements, the industry has developed important self-regulatory mechanisms. One example is the continuous ranking of analysts according to forecasting accuracy, but more importantly, the professional associations, such as the CFA Institute, require members to adhere to ethical codes and standards of professional conduct [13]. The impression of absolute freedom in modelling is illusory, in 
contrast with the actual continuous surveillance and strict professional responsibility of the modellers.

The responsibility for the modelling outputs and the reasonable use of results is on the modeller, not the model. The proper use of models is to support decisions, not to substitute reasoning or to dictate conclusions. Motivated by the recent financial crisis, the Financial Modellers' Manifesto was published in 2009 by prominent financial mathematicians [18]. Even though it is devoted to algorithmic, well-defined models of financial securities, it contains the principles that are also applicable to the construction and use of CFMs, summarised in The Modellers' Hippocratic Oath. It postulates the distinction between the financial reality and its modelled representation; prohibits overconfidence in models and promotion of such beliefs; forbids unreasonable model oversimplifications; and calls for conscious conduct. In accordance with these principles, and given the extensive use of CFMs as supporting tools for influential decisions, it is imperative for CFMs to remain within a comprehensive structure, built for specific objects, and based on educated judgement.

\section{Conclusion}

This paper presents the observed extensive use of CFMs in corporate finance, equally for corporate business planning and fundamental investment analysis. Such models are regarded by business professionals as important decision supporting tools due to exhibited descriptive, explanatory and predictive qualities.

The CFM output projections are to be considered as a possible hypothetical future, consistent with other model assumptions, and suitable for scenario and simulation analysis. The assumptions are predominantly based on expert judgment, while the models are customised for a specific company. The observed practice indicates that automatisation, algorithmisation or generalisation can be significantly detrimental to CFM's explanatory and predictive strengths. Colloquially expressed, a good CFM is tailor-made, hand-made unicum; an expensive craftwork. Thus, the emphasis is on the responsibility of modeller as well as the awareness of the recipients, particularly under overconfident market circumstances.

Recent academic research is mostly restricted to publicly available model outputs by equity analysts. Even though expectedly weaker than private, due to the lack of confidential inside information, published equity analysts' forecasts are repeatedly confirmed superior relative to predictions by other methods, such as univariate time series models. This paper argues that the use of CFMs, as described herein, contributes significantly to this advantage. It has been shown that, by construction, CFMs possess important forecast error variance reduction properties. 
The suggestion therefore for future research into equity analysts' forecasts is to incorporate analyses of underlying financial models. Increasing the understanding of relations between the model characteristics and output properties importantly requires analysing model forecasts in the context of expectations theory, as well as studying and testing regular model designs for various statistical implications. A limitation of this paper is identification and discussion of only two significant CFM features: judgmental assumptions and variance reduction mechanics. The recommendation is for further research to determine other properties, both beneficial and non-beneficial for the quality of CFMs. Such research may

eventually lead to codification of modelling elements and procedures, in order to improve scientific foundations of CFMs.

\section{References}

[1] Ackert, L. F. and Hunter, W. C. (1995). Rational expectations and security analysts' earnings forecasts. Financial Review, 30(3), 427-443.

[2] Aljinović, Z., Marasović, B. and Šego, B. (2011). Financijsko modeliranje (2nd ed.). Split: Ekonomski fakultet Sveučilišta u Splitu.

[3] Ascoli, E. (2013). Modeling (4th ed.). London: Adkins, Matchett \& Toy.

[4] Avon, J. (2013). The Handbook of Financial Modeling: A Practical Approach to Creating and Implementing Valuation Projection Models. New York: Apress.

[5] Barber, B., Lehavy, R., McNichols, M. and Trueman, B. (2001). Can investors profit from the prophets? Security analyst recommendations and stock returns. The Journal of Finance, 56(2), 531-563.

[6] Benninga, S. (2014). Financial Modeling (4th ed.). Cambridge, MA: MIT Press.

[7] Bonini, S., Zanetti, L., Bianchini, R. and Salvi, A. (2010). Target price accuracy in equity research. Journal of Business Finance \& Accounting, 37(910), 1177-1217.

[8] Bradshaw, M. T. (2011). Analysts' forecasts: what do we know after decades of work? Available at SSRN: http://ssrn.com/abstract=1880339 [Accessed 18/09/16].

[9] Brav, A. and Lehavy, R. (2003). An empirical analysis of analysts' target prices: Short-term informativeness and long-term dynamics. The Journal of Finance, 58(5), 1933-1968.

[10] Brown, L. D., Hagerman, R. L., Griffin, P. A. and Zmijewski, M. E. (1987). Security analyst superiority relative to univariate time-series models in forecasting quarterly earnings. Journal of Accounting and Economics, 9(1), $61-87$. 
[11] Brown, L. D. and Rozeff, M. S. (1978). The superiority of analyst forecasts as measures of expectations: evidence from earnings. The Journal of Finance, $33(1), 1-16$.

[12] Call, A. C., Chen, S. and Tong, Y. H. (2013). Are analysts' cash flow forecasts naïve extensions of their own earnings forecasts? Contemporary Accounting Research, 30(2), 438-465.

[13] CFA Institute (2014). Standards of Practice Handbook (11th ed.). Charlottesville, VA: CFA Institute.

[14] Charnes, J. M. (2012). Financial modeling with Crystal Ball and Excel (2nd ed.). Hoboken, N.J.: John Wiley \& Sons.

[15] Cheng, Y., Liu, M. H. and Qian, J. (2006). Buy-Side Analysts, Sell-Side Analysts, and Investment Decisions of Money Managers. Journal of Financial and Quantitative Analysis, Vol. 41 No. 1, 51-83.

[16] Clements, M. P. and Hendry, D. F. (2002). An Overview of Economic Forecasting. In Clements, M. P. and Hendry, D. F. (Eds.). A companion to economic forecasting (pp. 1-18). Malden, MA: Blackwell Publishing.

[17] Damodaran, A. Probabilistic Approaches to Risk: Scenario Analysis, Decision Trees and Simulations. Available at: http://people.stern.nyu.edu/adamodar /pdfiles/papers/probabilistic.pdf [Accessed 18/09/16].

[18] Derman, E. and Wilmott, P. (2009). The financial modelers' manifesto. Available at SSRN: http://ssrn.com/abstract=1324878 [Accessed 24/09/16].

[19] Dym, C. L. (2004). Principles of Mathematical Modeling (2nd ed.). Amsterdam; Boston: Elsevier Academic Press.

[20] Frazier, G. D. (1969). A Corporate Long Range Planning Model. Business Economics Vol. 4, No. 4, 62-65.

[21] Garthwaite, P. H., Jolliffe, I. T. and Jones, B. (2002). Statistical Inference (2nd ed.). New York: Oxford University Press.

[22] Gleason, C. A., Bruce Johnson, W. and Li, H. (2013). Valuation model use and the price target performance of sell-side equity analysts. Contemporary Accounting Research, 30(1), 80-115.

[23] Graham, B. and Dodd, D. L. (2008). Security Analysis: Principles and Technique (6th ed.). New York: McGraw-Hill.

[24] Groysberg, B., Healy, P. and Chapman, C. (2008). Buy-side vs. sell-side analysts' earnings forecasts. Financial Analysts Journal, Vol. 64.4, 25-39.

[25] Hobbs, J. and Singh, V. (2015). A comparison of buy-side and sell-side analysts. Review of Financial Economics, Vol. 24, 42-51.

[26] Koop, G., Poirier, D. J. and Tobias, J. L. (2007). Bayesian Econometric Methods (Econometric Exercises vol. 7). New York: Cambridge University Press.

[27] Kosy, D. W. and Wise, B. P. (1984). Self-Explanatory Financial Planning Models. In Proceedings of the 4th National Conference on Artificial Intelli- 
gence, AAAI-84 (pp. 176-181). Austin, TX: Association for the Advancement of Artificial Intelligence.

[28] Levy, R. A. (1966). Conceptual Foundations of Technical Analysis. Financial Analysts Journal, Vol. 22.4, 83-89.

[29] Li, W. and McDowell, E. A. (2011). Investor affect, investor status and the influence of analyst reports. Journal of Finance and Accountancy, 8, 1.

[30] Loh, R. K. and Stulz, R. M. (2011). When are analyst recommendation changes influential? Review of Financial Studies, 24(2), 593-627.

[31] McKinsey \& Company, Koller, T., Goedhart, M. and Wessels, D. (2010). Valuation: Measuring and Managing the Value of Companies (5th ed.). Hoboken, N.J.: John Wiley \& Sons.

[32] Merton, R. C. (1995). Influence of mathematical models in finance on practice: past, present and future. In Howison, S. D., Kelly, F. P. and Wilmot, P. (Eds.). Mathematical Models in Finance (pp. 1-14). London: Chapman \& Hall for The Royal Society.

[33] Michaely, R. and Womack, K. L. (1999). Conflict of interest and the credibility of underwriter analyst recommendations. Review of financial studies, 12(4), 653-686.

[34] Mills, T. C. and Markellos R. N. (2008). The Econometric Modelling of Financial Time Series (3rd ed.). Cambridge: Cambridge University Press.

[35] Minch, R. P. (1989). Logic Programming as a Paradigm for Financial Modeling. MIS Quarterly, Vol. 13 No. 1, 65-84.

[36] Naylor, T. H. and Gattis, D. R. (1976). Corporate planning models. California Management Review, 18(4), 69-78.

[37] Naylor, T. H. and Schauland, H. (1976). A survey of users of corporate planning models. Management Science, 22(9), 927-937.

[38] Newton, J. K. (1985). The Decision Support Role of Operational Research in Corporate Planning. In Rand, G. K. and Eglese, R. W. (Eds.). Further Developments in Operational Research. Oxford: Operational Research Society, Pergamon Press.

[39] O'Brien, P. C. (1988). Analysts' forecasts as earnings expectations. Journal of accounting and Economics, 10(1), 53-83.

[40] Ramnath, S., Rock, S. and Shane, P. B. (2008). Financial Analysts' Forecasts and Stock Recommendations: A Review of the Research. Hanover, MA: Now Publishers.

[41] Ramnath, S., Rock, S. and Shane, P. (2008a). The financial analyst forecasting literature: A taxonomy with suggestions for further research. International Journal of Forecasting, 24(1), 34-75.

[42] Richardson, S., Teoh, S. H. and Wysocki, P. D. (2004). The walk-down to beatable analyst forecasts: The role of equity issuance and insider trading incentives. Contemporary accounting research, 21(4), 885-924. 
[43] Robert, C. and Casella, G. (1999). Monte Carlo Statistical Methods. New York: Springer Science \& Business Media.

[44] Sarapa, N. (1992). Teorija vjerojatnosti (2nd ed.). Zagreb: Školska knjiga.

[45] Sengupta, C. (2004). Financial Modeling using Excel and VBA. Hoboken, N.J.: John Wiley \& Sons.

[46] Shim, J. K. and McGlade, R. (1984). The use of corporate planning models: past, present and future. Journal of the Operational Research Society, 35(10), 885-893.

[47] Shim, J. K. and Siegel, J. G. (2007). Handbook of Financial Analysis, Forecasting, and Modeling (3rd ed.). Chicago: $\mathrm{CCH}$.

[48] Siegel, J. G. and Shim, J. K. (2000). Accounting Handbook (3rd ed.). New York: Barron's Educational Series.

[49] Stabile, D. R. (2005). Forerunners of Modern Financial Economics: A Random Walk in the History of Economic Thought. Cheltenham: Edward Elgar Publishing.

[50] Stein Fairhurst, D. (2012). Using Excel for Business Analysis: a Guide to Financial Modelling Fundamentals. Singapore: John Wiley \& Sons.

[51] Thomsett, M. C. (1998). Mastering Fundamental Analysis. Chicago: Dearborn Financial Publishing.

[52] Vondraček, Z. (2008). Financijsko modeliranje - predavanja. Available at: https://web.math.pmf.unizg.hr/ vondra/2013-14.html [Accessed 06/09/16].

[53] Wild, J. J. (2011). Measurement of a financial model of the firm: A field study. Journal of Applied Business Research (JABR), 9(4), 83-92.

[54] Zekić, M. (1996). Neural networks for time-series predictions in finance and investing. In Hunjak, T., Martić, Lj. and Neralić, L. (Eds.). Proceedings: 6th International Conference on Operational Research. Zagreb: Croatian Operational Research Society.

[55] Zitzewitz, E. (2001). Measuring herding and exaggeration by equity analysts and other opinion sellers. Available at SSRN: http://ssrn.com/abstract $=405441$ [Accessed 24/09/16]. 